\title{
DEVELOPING A MODEL FOR THE TEACHING AND LEARNING OF FLUID MECHANICS AT AN OPEN DISTANCE UNIVERSITY
}

\author{
Richard Naidoo, Jane Ramanamane, Unisa, South Africa
}

\begin{abstract}
The study explores the developing of a model for the teaching and learning fluid mechanics at open distance university. Most of the students are employed. The model emphases blended learning, flexible learning and student-cantered learning. Fluid mechanics it a module offered at first level of mechanical engineering, which consists of two formative assessment, one submissive assessment and laboratory assignment. This study employed an activity theory as a framework. The quantitative approach was used to collect data. Data consists of student's assignments (theory and practical) final examination scores. The results indicated average pass rates during 2015 and 2017. However, the pass rates during 2016 was good. It is recommended that cognitive analysis of the student responses could improve the performance rate, quality and enhancement to teaching and learning.
\end{abstract}

Keywords: fluid dynamics, ODL, Blended learning, engineering, open distance learning.

\section{Introduction}

Fluid mechanics is a Mechanical Engineering module, desired to bring the understanding of the forces and flow within fluids. Due to the rapid technological developments, this model has shifted from fully open distance learning to the blended learning approach. The blended learning is known a flexible learning and teaching method, which integrates the online course and face-to-face modes to achieve the desired learning objectives for student. This module consists of three categories:

- $1-28 \%$ Web facilitated;

- $\quad 29-80 \%$ Course content delivered online (blended);

- $80-100 \%$ Delivered face-to-face.

The assessment model consists of the formative assessment of one assignment and one practical (weight 20\%). And one summative assessment in a form of examination (weight $80 \%)$. 
A Blended Learning Approach (BLA), it is now a field of interests for most ODL (Open Distance Learning) researchers. BLA it is found to be more attractive because of its flexibility and cost-effectiveness, this is because it can serve to tranquilize the loneliness of rural students by simply acknowledging their existence and their challenges with module. A study on teaching and learning of fluid mechanics by applying a blended learning approach (BLA) was investigated by Rahman (2017), where the grading metrics and SFU (student feedback on unit) survey method was used for data analysis, It was found that BLA has improved the learning experience of the fluid mechanics students.

Furthermore, Blended Learning Approach should be integrated with Student-Cantered Learning. Weimer (2013) indicated that the balance of power it is very important for this teaching, learning and student objectives as it enhances their knowledge about the module. A Blended Learning Approach seeks to promote the effective and Student Centred Learning, where students are also given the opportuning to interact by exchanging knowledge about the content of fluid mechanics on the discussion forum, what'sup groups, etc.

In addition a review of teaching and learning fluid mechanics was addressed by Rahman (2017), where the study employed quantitative approach for data collection, according to the outcomes it was found that "student-cantered approach" was effective for teaching and learning of fluid mechanics. And it was also found that with the intervention of blended learning approach teaching fluid mechanics could even be more effective.

However, the aim of blended learning it is not just to improve the pass rate but also to enhance the learning and the knowledge of the student studying fluid mechanics. Even though the blended learning approach enables good interaction between students and lecturers of fluid mechanics, however we still need to consider the students opinions about the online teaching over the traditional teaching approach. A study of identifying the student opinions about the blended learning approach in fluid mechanics course was investigated by Sarvar et al. (2018), where the questionnaire method was used for surveying, it was found that student prefers the blended learning for fluid mechanics especially where high demanding cognitive skills are needed.

Also a Blended Learning Approach to Teaching First Year Engineering was investigated by Sarvar et al. (2018), where evaluation method included student questionnaires and structured interview together with overall student performance analysis, from the examination result it was concluded that the improved performance of the student was due to a blended learning approach.

Moreover, the Perceptions of Students towards Online Learning was found to be a very interesting topic by Huss and Eastep (2017), where the questionnaire approach was 
employed, and the study confirmed that students have definite perceptions about online education and what they believe to be the necessary components for their success in this environment. However, there is no doubt that blended learning approach is best appreciated by both students and lecturers of fluid mechanics in various universities because of the benefits it brings to this module. The purpose of this study is to investigate teaching and learning model given below as Figure 1 in fluid mechanics in mechanical department using ODL methods.

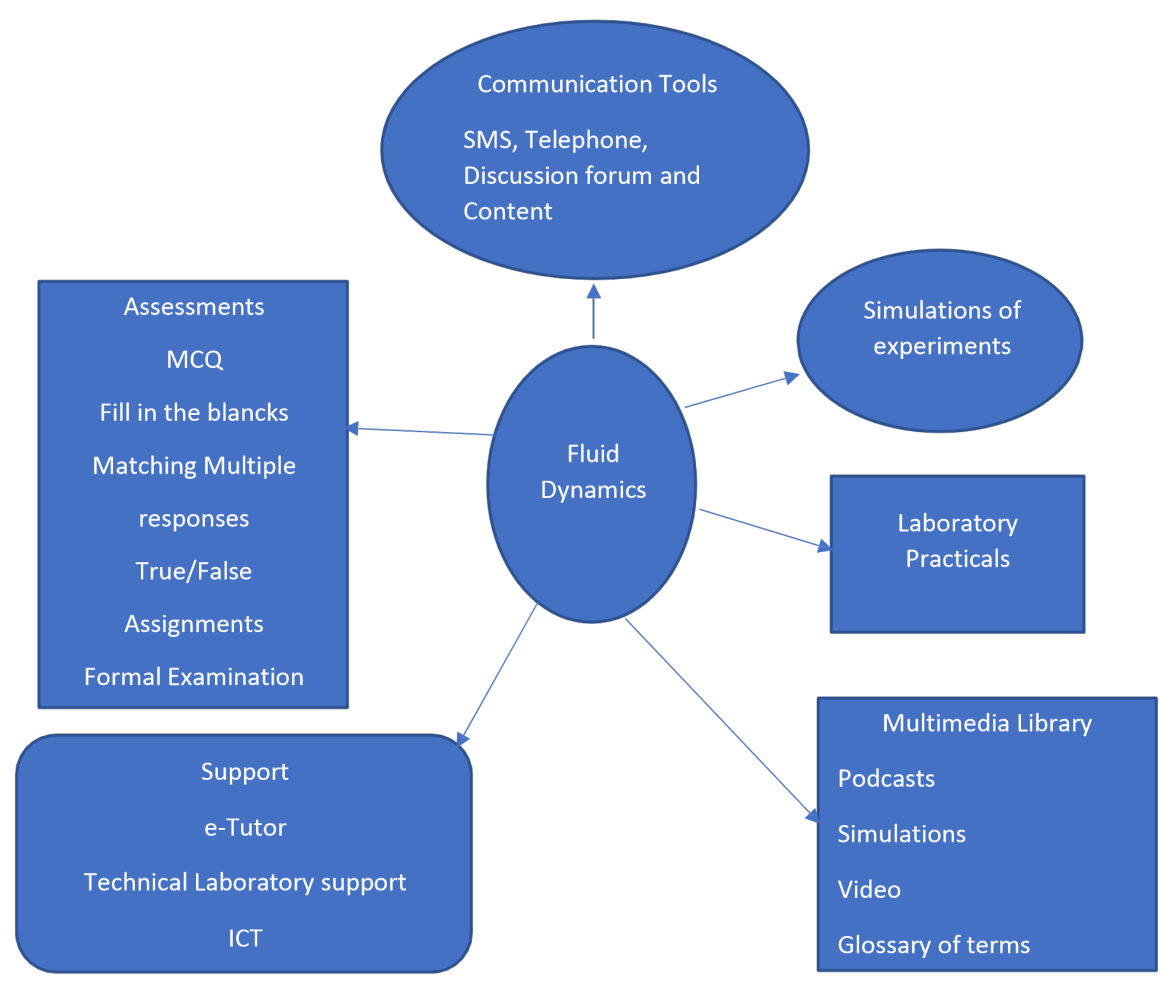

Figure 1. ODL fluid dynamic model

Role of e-Tutor:

- Illustrate complex problems;

- Summarizes understanding;

- Contact group discussions;

- Illustrate we solutions etc.

Announcements:

- Communication with students;

- Updates;

- Alert when there are changes/upgrades.

Discussion Forum:

- For flexible communication. 


\section{Theoretical Framework}

This study is guided by the connectivism theory of learning. A study of Learning Theory for the Digital Age was investigated by Siemens (2014), and he reported that connectivism theory provides insight into learning skills and tasks needed for learners to flourish in a digital era. Which simply means the knowledge travels around network of connections. This theory promotes e-learning, which is the most popular research of nowadays. Yuen and Yaoyuneyong (2011) also showed a great input into towards learning, by conducting a case study of exploring the integration of social media into online courses, where online questionnaire method was employed, and the results of the study showed that students found e-learning approach very positive and encouraging because of its flexibility such as (easily access course content, interact with content and with others, construct new knowledge, and collaborate with others to form a learning network).

Furthermore, e-learning approach enhances teaching, learning and promotes blended learning approach. Prior research clearly indicated that the connectivism theory should be employed by this study to enhance blended learning approach of teaching and learning of fluid mechanics.

\section{Methodology}

The focus of this study is based on fluid mechanics first level, which is currently a semester course in mechanical engineering at UNISA. The student population is approximately between 60 and 90. The assessment model for this module consists of the formative assessment of two written and practical assignment (weight 20\%), and one summative assessment in a form of examination (weight 80\%). The quantitative method was employed by this study, where the overall performance of students was obtained from the final examination data. The evaluation includes the number of student registered, assignment performance and final exam performance. A sufficient support for this module is it provided through the Learning Management System (LMS) known as MyUnisa. Savar et al (2018) indicated that, through LMS it is convenient to determine the activeness of the students, and it also allows flexible interaction between students and the lecturer

\section{Results}

The overall students' performance results are displayed in Figure 2 below for both the assignments and examination. From the results it could be clearly seen that the intervention tools have the positive impact towards the student performance rate, however further enhancement of the interventions is required for this module. The results below demonstrate only the number of students passed during the semester over the total number of the students registered. 
The historic performance is represented by a bar graph below, where the red area represents the poor performance of the students, yellow area represents the average performance of the students and the green area represent the enhanced performance of the students.

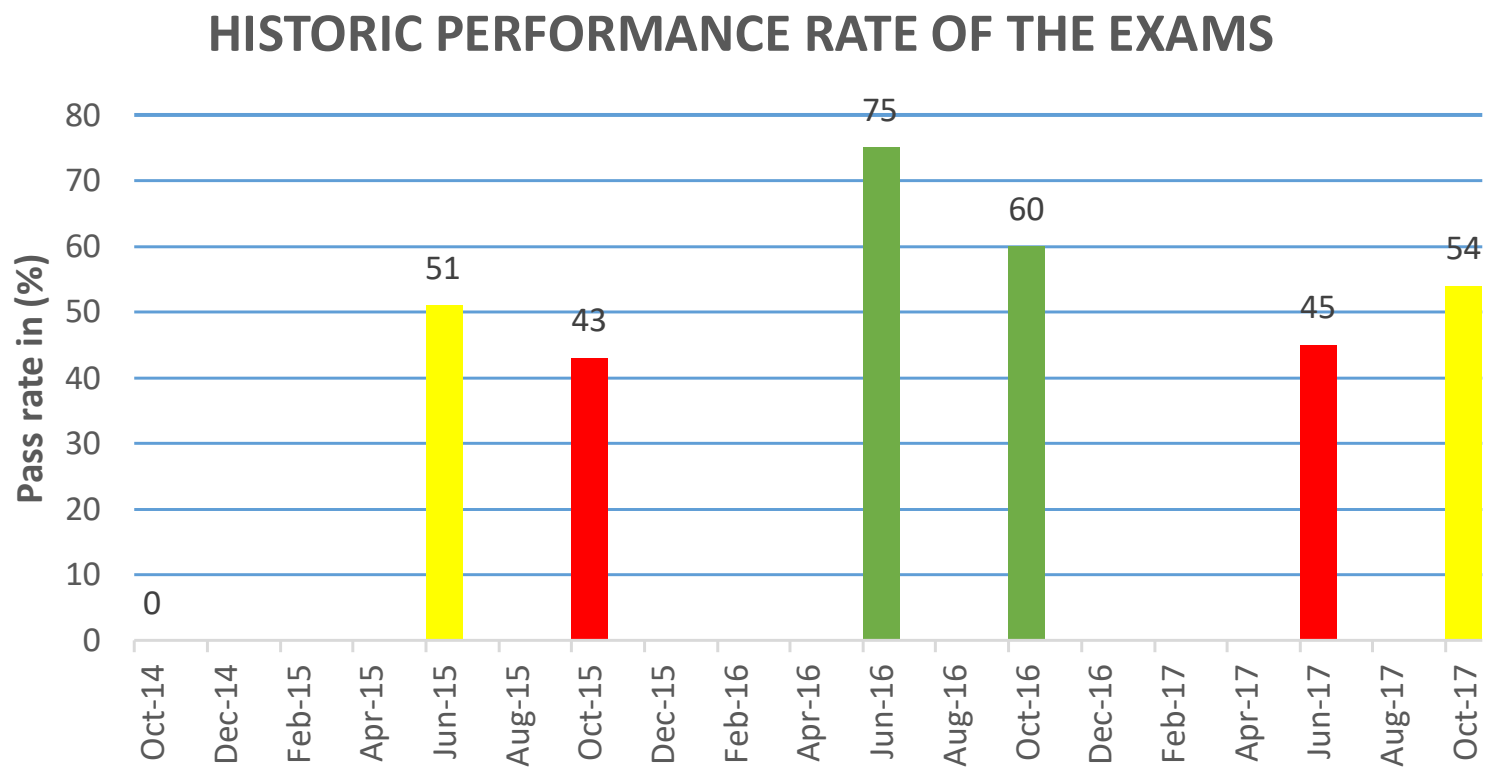

No. of years and semesters

Figure 2. Examination results

\section{Discussion and Conclusion}

From the results enhancement of the interventions is required for this module. Study of fluid mechanics seem to be very challenging for students. This type of performance requires more interventions, most importantly to encourage the student to utilise MyUnisa platform for their study.

Due to the low pass rate of fluid mechanics it is recommended a cognitive analysis be employed for this module and encourage more of student cantered method of learning (Wright, 2018). However, BLA portray encouraging results towards teaching and learning of fluid mechanics (Rahman, 2017). Majority of the students have over 50\% rates.

The purpose of the study was to investigate the effectiveness of the fluid model which is encourages flexible teaching and learning which could help to enhance the quality, improve performance, teaching and learning of the fluid mechanics. From the results it can be concluded that during the past years, this module has been challenging for the students to learn. 


\section{References}

Huss, J. A., \& Eastep, S. (2013). The perceptions of students toward online learning at a Midwestern university: What are students telling us and what are we doing about it? I.E. Inq. Educ., 4(2), 1-20.

Rahman, A. (2017).A blended learning approach to teach fluid mechanics in engineering. Eur. J. Eng. Educ., 42(3), 252-259.

Rahman, A., \& Al-Amin, M. (2017). Teaching of Fluid Mechanics in Engineering Course. Curric. Des. Classr. Manag., 1093-1101.

Šavar, M., Krizmanic, S., \& Korbar, R. (2018). Students opinion about e-learning in Fluid mechanics courses. IOP Conf. Ser. Mater. Sci. Eng., 393, 12112.

Siemens, G. (2014). Connectivism: A Learning Theory for the Digital Age. Int. J. Instr. Technol. Distance Learn., 1, 1-8.

Weimer, M. (2013). Learner Centered Teaching: Five Key Changes to Practice.

Wright, G. (2011). Student-Centered Learning in Higher Education. Int. J. Teach. Learn. High. Educ., 23(3), 92-97.

Yuen, Y., \& Yaoyuneyong, G. (2011). E-Learning 2.0. 263-278 